\title{
Evaluating Web Accessibility of Educational Websites
}

\author{
http://dx.doi.org/10.3991/ijet.v10i4.4518 \\ Bayan Abu Shawar \\ Arab Open University, Amman, Jordan
}

\begin{abstract}
Web accessibility concerns of building websites that are accessible by all people regardless of their ability or disability. The W3C Web Accessibility Initiative (WAI) has been established to raise awareness of universal access. WAI develops guidelines which can help to ensure that Web pages are widely accessible. Assistive technology is used to increase, improve, and maintain capabilities of disabled persons to execute tasks that are sometimes difficult or impossible to do without technical aid. Also it helps them achieve their scholar, professional and social activities. This paper exposes an approach to investigate accessible contents of educational websites to ensure and measure its compliance with accessibility standards for visually impaired people. This study focuses on studying existing standards and investigating its applicability on educational institute websites. This will increase accessibility on e-learning materials that are provided by educational institutes. In this paper a sample of websites at selected universities in Jordan are evaluated in terms of accessibility in comparison to some universities websites in England and Arabic region. Results show that accessibility errors of universities websites in Jordan, and Arab region exceed the ones in UK by 13 times, and 5 times consequently.
\end{abstract}

Index Terms-WAI, e-learning, website accessibility, WCAG, Wave tool.

\section{INTRODUCTION}

The digitization of many public services such as shopping, banking, and library which facilitate our daily life, allow people with disabilities to live in almost the same way as those who are not disabled [2]. With the huge amount of information available via the net, the academic people consider the Internet as an educational tool, which open new paradigms in learning as distance learning, and e-learning.

One aim of most governmental and educational institutions is to provide equate life for disable learner. Elearning is considered as one of the solutions for this group of people, the e-learning philosophy aims to provide information and learning materials to learners any where any time. For example the learners who have physical disability like wheelchair-bound can access any elearning resources without the need to move to university campus, and navigating around the buildings to lectures' rooms which might be difficult for them. However, there are other disabilities that should be considered when building an online web-page, or an e-learning platform such as [8]:

- Vision problems, blindness, and colour blindness,

- Hearing impaired,

- Cognitive or neurological disability.
Web accessibility refers to "the practice of creating websites that are usable by people of all abilities or disabilities". [32] In a European survey on e-learning for disabled people1, over half cited that their students suffer form hearing or visual disabilities; $17.5 \%$ listed problems with speech, over $30 \%$ mentioned learning difficulties; around a third respondents described the disability as physical, and $15 \%$ stated other types including mental illness, psychiatric problems, brain injury, and behavioral difficulties.

The Royal College for the Blind [21] addressed that elearning via the Internet is well enable visually-impaired students to access more materials and work more independently than they could using traditional method. Moreover, the Computer Mediated Communications (CMC) help disabled learners in different aspects by improving the social life by enabling them communicating through emails, and chatting with other students in which learners overcome the problems of disability [4].

Barrett [3] stated the e-learning should not only be used as a mode of instructions, but also as a strategic tool for breaking down current educational barriers faced by students with disabilities in educational institutions. "As promising as the new technology is, there is still a lot of work to be done before e-Learning is at its most effective, not least in raising public awareness" [10].

As a result, all e-learning website should be focused on how to make their websites accessible to serve disabled students.

The aim of this paper is to check if Universities' websites in Jordan are accessible by the disabled learners and how much are they in compliant with WAI, in comparison with others in Arab region and UK. Web accessibility guidelines and e-learning are presented in section two, the guidelines to create an accessible website for disabled are outlined in section 3, evaluating of web accessibility of some universities websites in Jordan, Arabic region and UK are discussed in section four. Finally the necessity of web accessibility and conclusion are presented in section 5 and 6 respectively.

\section{WEB ACCESSIBILITY AND E-LEARNING}

The Web Accessibility Initiative (WAI) is a group of the World Wide Web Consortium (W3C) who defined the first version of the Web Content Accessibility Guidelines (WCAG 1.0) in 1999. WCAG provides 65 checkpoints that cover 14 guidelines which facilitate developing an accessible website. These checkpoints are distributed into three levels: A, AA, AAA which has priority1, 2, and 3

\footnotetext{
http://www.disabilityworld.org/09-10_01/access/elearning.shtml
} 
consequently [22]. Based on these levels, the website can be categorized as follows:

- Website is impossible to be accessed if it does not satisfy priority 1 (level A),

- Website is difficult to be accessed by some users if it does not satisfy priority 2 (Level AA)

- Website is somewhat difficult to be accessed if it does not satisfy priority 3 (Level AAA)

Version 2 of WCAG (WCAG 2.0) added other principles about web content accessibility: "content should be perceivable, Operable, understandable and Robust" [19].

Mlynarczyk [17] lists some web accessibility myths that a website developer should take into consideration based on WCAG gridlines:

- Providing captions and transcripts for videos, alternative text descriptions for images, and mechanism to control slideshow;

- Building websites with clear layout, consistent navigation and meaningful link names, to make them accessible to people with cognitive disabilities

- Web accessibility should not be optional as in England, Scotland, and Wales where accessibility is forced by law.

- The need for human judgment to evaluate WCAG checkpoints because available evaluation tools are not sufficient by its own. For example the image has a text description, a human judge is needed to decide whether is meaningful or not.

- Building ac accessible website rely on three groups of stakeholders: website commissioners who own and manage website, web developers who designed develop website, and finally the accessibility experts who may advice the first two groups, and test the website as agreed by other researchers [18].

- There are many benefits gaining from making website accessible such as:

- Improving web websites' search engines ranking,

- Increasing website use since accessible websites are easier to fin and use,

- Decreasing cost including maintenance cost, server cost, cost of upgrading to new technologies, etc.

- accessibility increase usability of a website,

○ Improving interoperability.

The e-Learning is defined as " use of internet technology for the creation, management, making available, security, selection and use of educational content to store information about those who learn and to monitor those who learn, and to make communication and cooperation possible." [15]. Based on this, the web is considered one of the main channels to deliver educational materials which necessitate applying WAI guidelines to make learning materials accessible by disabled learners.

In addition to WCAG guidelines, Kelly et al [13] added other factors that should be considered in building elearning websites such as: pedagogic issues, infrastructure issues, student learning style, and other technical factors that satisfy learner needs.

However, researchers believe that there are still access difficulties via websites, such as [16]:

- The font is too small and could not be enlarged
- Buttons, and figures without explanatory text,

- In sufficient colour contrast between foreground and background

In the same manner, Kamollimsakul et al., [12] investigated the effect of font type and size on skim reading web pages especially for Thai language. They found out that the font type effect reading time per web page, and that both font type and size have a significant effect on reader preferences.

\section{CREATING WEB ACCESSIBILITY FOR DISABLED}

$\mathrm{Li}$ and Sun [14] agree that the main aim of e-learning is that the "learning process can be carried at any time, anywhere, by any one via any media and anyway". According to this e-learning websites should allow learners with disabilities to access more materials and work more indecently than they could by using traditional methods [20]. This leads to what is known as web accessibility that "refers to the practice of making websites usable by people of all abilities and disabilities"2. Accessibility in relation to e-learning is understood as "ensuring that learners are not prevented from accessing technologies or the content and experience offered by technologies on the grounds of their disability" [25].

Wattenberg [26] mentioned two ways to create an accessible website:

- Internet providers self-regulate their services in order to make it accessible,

- Allowing market forces to regulate the internet.

The web development is composed of four parts that should be taken into consideration to make this web accessible [29], [23]:

- Web content which is the textual; visual or aural content such as: text, images, sounds, and presentation [1];

- Web browsers which are any software that gave a user access to website and provides graphical user interface to enable user to communicate with the browser such media players [9];

- Assistive technology which is a generic term that includes assistive, adaptive, and rehabilitative devices and the process used in selecting, locating, and using them such as: screen readers, alternative keyboards, switches, scanning software [5];

- Authoring tools which are any software or collection of software components that authors could use to create or modify Web content for use by other people [11].

According to Prougestaporn [20], it was necessary that several different components of Web development and interaction should worked together to be accessible to people with disabilities.

To ensure that the Web content have fair and equitable access to all people there are some checkpoints that are prepared by the W3C Web Content Accessibility Guidelines 1.0 [30] that must be considered, which could be summarized as follows:

- All text material should be available via sound for people who have vision problems or blindness.

\footnotetext{
${ }^{2}$ http://en.wikipedia.org/wiki/Web accessibility
} 
- There should be text based description for all nontext contents: figures, pictures, and graphs.

- All sound resources should be transcripted, so people who have hearing impaired can access it.

- Be sure that the level of the language is simple, and appropriate for target audience.

- Avoid causing the screen to flicker as this can trigger epileptic seizures.

WebAim(Web accessibility in Mind) [29] recommend additional guidelines that suits people with hearing impaired:

- Videos must be subtitled or the transcript must be enclosed.

- Text is clear and easily readable.

To make Web browsers and other user agents accessible, the User Agent Accessibility Guidelines or UAAG necessitates that [11]:

- User agents and Web browsers have to follow applicable specifications and conventions, to facilitate access by assistive technologies,

- Be sure that the user interface is perceivable, operable, and understandable.

Debevec and other researchers [7] highlight some additional guidelines that help hearing impaired people which are:

- Interface should be simple without too many additional options.

- Navigation should be in the same position through the site.

- No new windows should open automatically because this may confuse beginners.

- Language and terminology used should be simple.

In terms of assistive tools there are no clear guidelines for it, only concerns with providing enhancements and changed methods of interacting with the technology needed to support great independence for disabled learners.

Even though, there are a lot of input and output devices that help disable learners to access websites such as: screen readers, Braille displays, onscreen keyboards, and voice recognition. One of the barriers to access was the lack of authoring tools [24], the W3C has developed guidelines to guide the developers of authoring tools called authoring tools accessibility guidelines (ATAG) which includes [31]:

- Authoring tools must facilitate access by assistive technologies.

- Authoring tool user interface must be operable, perceivable and understandable.

- Production of accessible content must be enabled.

- Authors must be supported in the production of accessible content.

- Accessibility solutions must be promoted and integrated.

Based on the above, Websites developers; especially elearning ones; should take care off these components and how to make it accessible to all.

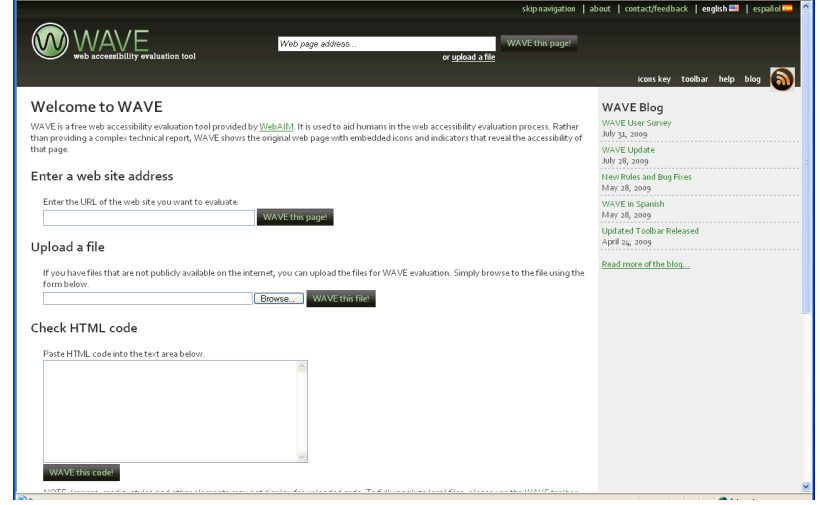

Figure 1. Wave Web accessibility tool

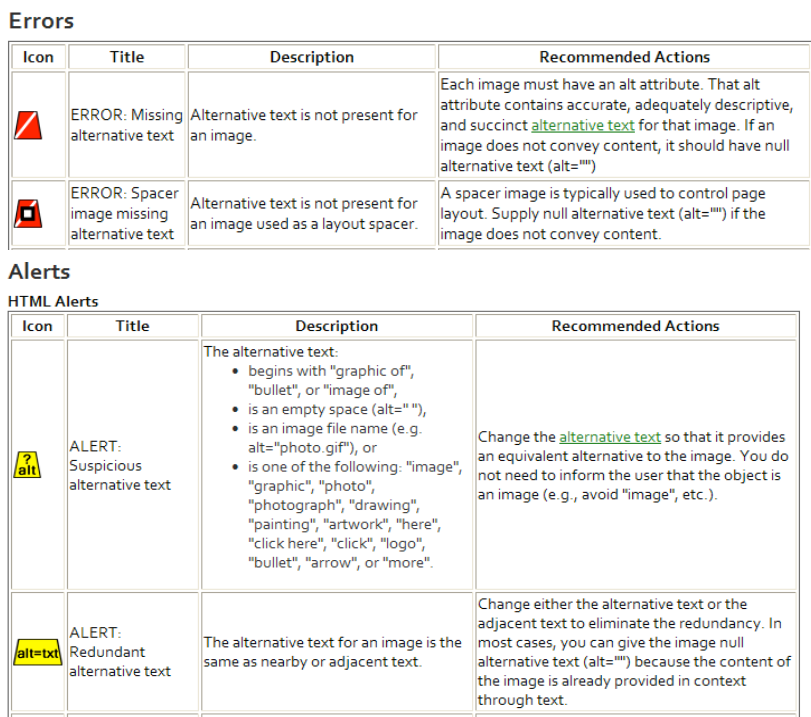

Figure 2. Brief description about Wave icons

\section{Evaluating Website AcCESSIBILITY}

To evaluate the accessibility of Universities of Jordan we use two approaches:

1. Using online detecting tools

2. Then doing manual checking

There are some of online detection tools such as: Wave[28], and Cynthia Says [6].

- Wave [28]: whish is an online tool that allows user to enter the web address of a current site as shown in figure 1, and produce a number of icons to user's page that allows users to check potential accessibility issues. Red icons indicate accessibility errors; the yellow ones indicates alerts; while the green icons indicates accessibility features; and all light blue indicate structural, semantic, or navigational elements. Some of Wave icons are shown figure 2.

- Cynthia Says [6] which allows user to enter the URL and produce a table of potential breaches, so you can check them manually after that.

\section{A. Samples of Jordanian Universities}

In Jordan, there are 30 universities, 10 of them are public universities and the rest are private ones. To check the accessibility of universities websites, we selected six universities that are the most popular ones, three of them are public and three are private. 
Table 1 and figure 3 show the selected Jordanian universities with their detected accessibility errors that are founded by Wave tool. The numbers in the table represent errors without including alerts.

We found that the number of accessibility errors appears in table 1 need double checking because some universities use different tools in building their websites, some tools force developers to fill for example text for each image. However, the Wave tool checks if there is a text describing each image but not able to check if this text has correct meaning, because of this we need manual checking for the correct description in terms of meaning.

Taking for example Jordan University of Science and Technology, figure 4 shows the output screen produced using Wave tool. By analyzing the output, we found that:

- There are 6 accessibility errors, most errors (red icons) represent empty links, a link without text description, and it is required to add meaningful text.

- There are 15 structural and semantic icons, where 13 of them indicate that a title attributes are used and it required ensuring that the title is brief and informative. The other two icons represent unordered lists which is required to ensure that an unordered (bulleted) list is appropriate for the context (i.e., the list items are parallel).

- Eight icons indicates that a table layout are found and it is required to ensure that the table is indeed a layout table and that it does not contain tabular data. If it is a layout table, eliminate all header cells (e.g., change $<$ th $>$ to $<$ td $>$ ).

- Only one green icon appears that represents that a text is found to describe a link, but still another checking is need to see if the description is informative.

- There are 25 alert icons (yellow one), 5 of theses alerts represent Link text does not make sense out of context, contains extraneous text (such as "click here"), or is the same as another link on the page, but links to a different location, these links need to be reworded in a representative way. Four of the alerts show that the links will open a new popup window; the user should be informed that the link will open a new window or in the same window. Six of the alerts indicate that there is an event handler which requires to:

○ Ensure that the event handler is device independent (does not require a mouse or keyboard) or that multiple event handlers are used to allow for both keyboard and mouse interactivity.

- Ensure that the actions that are performed as a result of these event handlers do not introduce accessibility issues.

- Ensure that this event is only attached to elements that can receive keyboard focus $(<\mathrm{a}>,<$ input $>$, etc.).

- If an onmouseover/out effect is only cosmetic (e.g. it causes an image to "glow" or to change color), no change is necessary.

o If the onmouseover/out effect exposes new content, this content will likely not be accessible to most assistive technologies. Provide a redundant, alternative way to access the same content or remove the mouse-over effect.
TABLE I.

NUMBER OF ACCESSIBILITY ERROS AT SOME UNVIVERSITIES' WEBSITES IN JORDAN

\begin{tabular}{|l|c|}
\hline \multicolumn{1}{|c|}{ University name } & Number of accessibility errors \\
\hline $\begin{array}{l}\text { Jordan university of Science and } \\
\text { Technology }\end{array}$ & 6 \\
\hline Irbid private University & 7 \\
\hline Israa University & 22 \\
\hline Mutah University & 28 \\
\hline Arab Open University & 28 \\
\hline Hashemite University & 72 \\
\hline
\end{tabular}

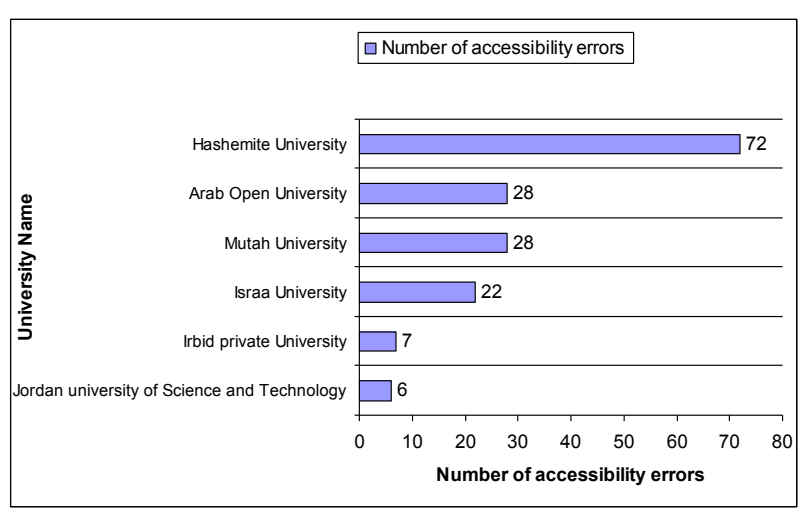

Figure 3. Statistics shows accessibility errors at some unviversities' Websites in Jordan

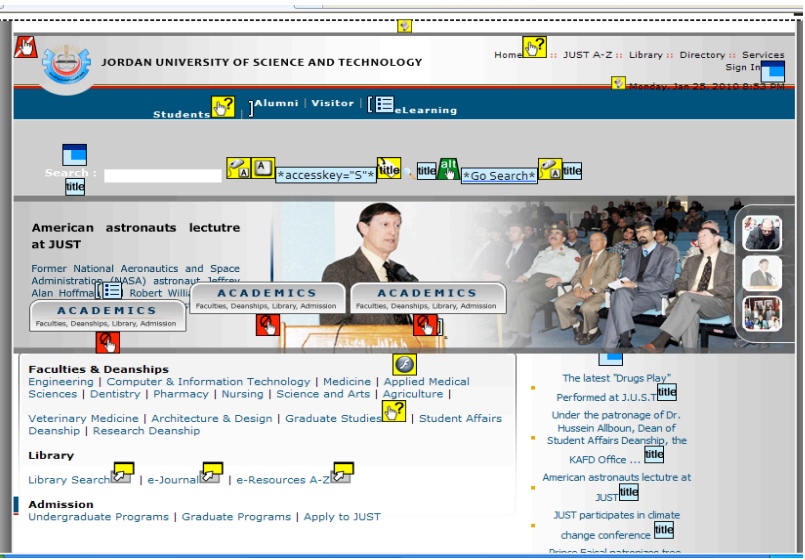

Figure 4. The Wave screen after inserting URL of Jordan University of Science and Technology

- Three alerts indicate the existence of Java script which requires ensuring that the JavaScript does not require the use of a mouse or introduce other accessibility issues.

- Another 3 alert icons indicate the existence of flash objects, and it is advised to do the following:

○ If the Flash object does not present content, hide it from screen readers.

- If content is presented, provide an HTML alternative and/or make the Flash object natively accessible, including providing captions for any embedded video-type content and ensuring that the Flash object is keyboard-accessible.

- One alert means a link to word document is found in which it is needed to provide an HTML alternative and/or ensure the Word document is natively accessible. 
- One alert indicates the missing of a form element label, and it is recommended to ensure that the title value adequately describes the functionality of the form element.

- One alert icon represents the missing of a headings or document structure. Another alert icon indicates that an access key is found and it is recommended not to use such access keys due to potential conflicts with browser and screen reader shortcut keys.

These errors and alerts not only occur in Jordan universities' websites, Arrigo [2] reported that the number of educational institutions which have provided courses and degree programs via e-learning mode has been growing grammatically since the middle of 1990s. However, Waits and Lewis [27] stated that 33\% of US institutions that offered distance courses in 2000-2001 did not know if their web sites followed accessibility guidelines, $28 \%$ followed the guidelines to a moderate extent and $18 \%$ followed the guidelines to a minor extent. Other research revealed that most of the US institutions for distance learning are inaccessible by disabled learners [24].

\section{B. Samples from UK Universities and from Arabic Universities}

In our study, the Wave tool was used to check accessibility in some universities in England and Arabic region. We selected well known universities distributed in different geographic locations Table 2 shows number of errors in six well know universities in England including Open University in UK which is the most popular one for distance learning. Most errors in these universities were missing a form label.

However number of accessible errors in six popular universities in different Arab regions; Saudi Arabia, Egypt, Qatar, Morocco, Lebanon, and Yemen were disappointed in comparison to UK ones as presented in table 3 .

Figure 5 shows average number of accessibility errors for each domain: UK, Jordan, and Arab region universities. Comparing average number of errors between these categories show that accessibility errors of universities websites in Jordan, and Arab region exceed the ones in UK by 13 times, and 5 times consequently. We may refer this to the fact that web accessibility is forced by law based on Equality Act 2010 (EQA) in England, Scotland, and Wales. This ensures that there should be polices, and laws for educational institutes in Jordan and in Arab region to be applied in terms of web accessibility. In general Web site developers need to take into consideration the disabled learners needs by modifying their websites to be accessible for able and disabled learners.

\section{THE NECESSITY OF WEB ACCESSIBILITY}

There is a great need for Web accessibility on education sector and in all domains since our daily life based on etechnologies, and social media communications. Even though there are new paradigms of learning nowadays such as distance learning, and e-learning, there are still access gap to educational websites between able and disabled learners. According to [32] and [33] statistics shows that over $10 \%$ of world population are disabled, $20 \%$ of Americans have disabilities that impair their access to websites, and internet contents, $12 \%$ of people in Canada
TABLE II.

NUMBER OF ACCESSIBILITY ERRORS AT SOME WEBSITES OF UK UNVIVERSITIES

\begin{tabular}{|l|c|}
\hline University name & Number of accessibility errors \\
\hline University of Oxford-UK & 1 \\
\hline Imperial College London & 1 \\
\hline The University of Edinburgh & 1 \\
\hline Open University-UK & 4 \\
\hline University of Leeds-UK & 1 \\
\hline University of Aberdeen & 4 \\
\hline
\end{tabular}

TABLE III.

NUMBER OF ACCESSIBILITY ERRORS AT SOME WEBSITES OF ARABIC UNIVERSITIES

\begin{tabular}{|l|c|}
\hline University name & Number of accessibility errors \\
\hline $\begin{array}{l}\text { King Fahd University of Petroleum } \\
\text { and Minerals-Saudi Arabia }\end{array}$ & 15 \\
\hline University of Qatar-Qatar & 8 \\
\hline Cairo University-Egypt & 14 \\
\hline Al-Akhawayn University-Morocco & 4 \\
\hline $\begin{array}{l}\text { American University of Beirut- } \\
\text { Lebanon }\end{array}$ & 12 \\
\hline Yemen University-Yemen & 13 \\
\hline
\end{tabular}

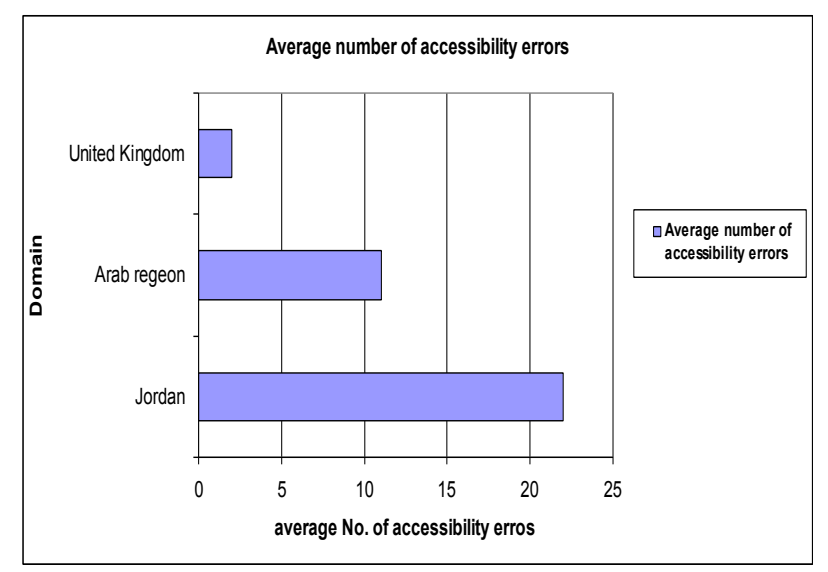

Average number of accessibility errors in each category

have some form of disability which limit their activities. Over $15 \%$ of whole populations in Europe have disabilities. Theses statistics scattered among different range of ages, for example $38 \%$ of the disabled people in Europe aged 16-34 across EU, 1 in 5 Americans aged 12 or older has a hearing loss, $11 \%$ of post-secondary U.S. students suffer from disabilities, 40.3 million citizen in U.S. aged 65 and over, those older people tend to have different forms of disabilities that limit their mobility, interfere with perceptions of world around them. In general around $10 \%$ of world populations live with disability. Figure 6 shows number of disabled people according to different categories of disabilities.

To allow those people to be more active and participate in society there is a need to provide disabled people with more effective and efficient access to information through accessible websites. Despite the fact that web accessibility targeted disabled people, but accessibility is useful for people with or without disabilities such as: [35]

- People working in a noisy environment, 
- People who use old technologies or low bandwidth connections,

- People who do not have or unable to use a keyboard or mouse,

- People who have poor English

\section{CONCLUSION}

We have presented in this paper the importance of making website content accessible and user friendly by disabled person. The W3C Web Accessibility Initiative (WAI) has been established to raise awareness of universal access. WAI develops guidelines which can help to ensure that Web pages are widely accessible. We also investigated accessible contents of educational websites to insure and measure its compliance with accessibility standards for visually impaired people. We are mainly interested by assistive technology aimed to facilitate the use of elearning by disabled person. Our preliminary study focused on studying existing standards and investigating its applicability on educational institute websites. We took Jordan universities as our domain of study and presented complete statistical outcomes along with recommendations to disseminate it. We also presented a comparison study among educational websites in Jordan, Arab region and some of UK universities. Results show that accessibility errors of universities websites in Jordan, and Arab region exceed the ones in UK by 13 times, and 5 times consequently.

The main outcome concluded that there are still needs to take more considerations of web accessibility to cover the needs of over $10 \%$ of world population (disabled people), mainly in Jordan and Arab countries.

\section{REFERENCES}

[1] Abdelzaher T. F., and Bhatti N. (1999). "Web content." COMPUT. NETWORKS.[Online]: http://www.cse.iitb.ac.in.

[2] Arrigo M. E-learning accessibility for blind students. In proceedings of International Conferences on Multimedia and ICT in Education. 2005.

[3] Barrett B.G. Using E-learning as a strategic tool for students with disabilities. http://www.wikieducator.org/images/9/98/PID_209.pdf

[Online]:

[4] Clark J., and Bellamy A. Internet utilization by persons with disabilities. In Proceedings of the CSUN 99: 14th"Technology and persons with disabilities" Conference, March 15-20,Los Angeles, California, USA (1999)

[5] Cook A.M. and Hussey S. (2001). Assistive Technologies: Principles and Practice, 2nd Edition. Mosby.

[6] Cynthia says website. http://www.icdri.org/test_your_site_now.htm

[Online]:

[7] Debevc M., Kosec P., and Holzinger A. E-Learning Accessibility for the Deaf and Hard of Hearing - Practical Examples and Experiences. In HCI in Work and Learning, Life and Leisure. Lecture Notes in Computer Science Volume 6389, 2010, pp 203-213.

[8] Designing e-learning accessibility. [Online]: http://designing.flexiblelearning.net.au/further_info/accessibility.h tm

[9] Dzbor M., Domingue J., and Motta E. (2003). "Magpie-towards a semantic web browser." Proceedings of ISWC, Springer [http://citeseer.ist.psu.edu/dzbor03magpie.html.

[10] European Survey on eLearning for Disabled people. [Online]: http://www.disabilityworld.org/09-10_01/access/elearning.shtml

[11] Information sheet: Learning platforms. 2008. [Online]: http://tlp.excellencegateway.org.uk/tlp/eguides/resource/EGuidesT rainingProgr LearningPlatforms/2.7_learning_platforms_information.doc

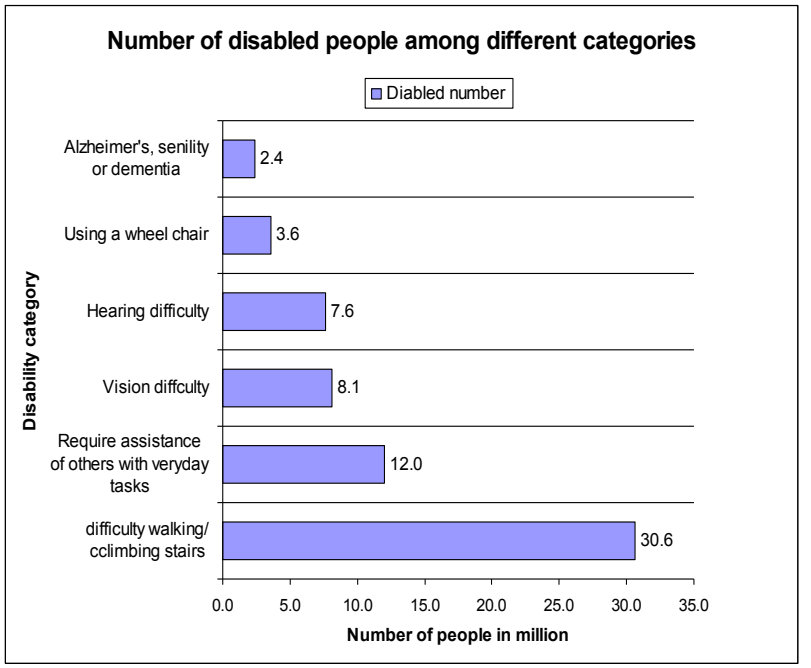

Figure 5. Number of dibaled people according to thier diabilities (taken from World Facts and Statistics on Disabilities and Disability Issues [34])

[12] Kamollimsakul S, Petrie H and Power C. 2014. Web Accessibility for Older Readers: Effects of Font Type and Font Size on Skim Reading Webpages in Thai. In Computers Helping People with Special Needs. PART 1 edn, vol. 8547 LNCS, Lecture Notes in Computer Science, vol. 8547, Springer, pp. 332-339, 14th International Conference on Computers Helping People with Special Needs (ICCHP 2014). http://dx.doi.org/10.1007/978-3-319-08596$\underline{852}$

[13] Kelly B., Phipps L., and Swift E. 2004. Developing a holistic approach for e-learning accessibility. Canadian Journal of Learning and Technology. Volume 30 (3).

[14] Li C., and Sun Y. Elearnign in information accessibility of disabled assistant technology.

[15] Mikic, F., \& Anido, L. "Towards a standard for mobile technology". In Proceedings of the International Conference on Networking, International Conference on Systems and International Conference on Mobile Communications and Learning Technologies (ICNICONSMCL'06) - Volume 00. Pp. 217-222, 2006

[16] Miesenberger K., Batusic M., Heumader P., and Stoeger B. (2012). MathInBraille Online Converter, in: Proceedings of the 13th international conference on Computers Helping People with Special Needs - Volume Part I p. 196-203; 07/2012, Springer, Austria http://dx.doi.org/10.1007/978-3-642-31522-0 29

[17] Mlynarczyk G. 2012. 7 Web Accessibility Myths. Humanising Technology Blog. [Online]: http://www.nomensa.com/blog/2012/7-web-accessibility-myths-2.

[18] Petrie, H., Power, C., Swallow, D., Velasco, C. A., Gallagher, B., Magennis, M., Murphy, E., Collin, S. and Down, K. The value chain of web accessibility: challenges and opportunities. In Proc. of ADDW 2011, Sun SITE Central Europe (2011).

[19] Power C, Freire A, Petrie H, Swallow D. 2012. Guidelines are only half of the story: accessibility problems encountered by blind users on the web". In Proceedings of the SIGCHI Conference on Human Factors in Computing Systems. Pp. 433-442. http://dx.doi.org/10.1145/2207676.2207736

[20] Prougestaporn, P. 2008. Web accessibility model for eLearning website. In proceedings of the fifth international conference eLearning for knowledge-based society. Pp. 43.1-43.5

[21] Royal College for the Blind. (2002). "DEMOS Project - Visually Impaired Students and E-Learning: Frequently Asked Questions." Online Materials for Staff Disability Awareness. [Online]: http://jarmin.com/demos/resource/rncb/print.html.

[22] Rømen, D. and Svanæs, D. Evaluating web site accessibility: validating the WAI guidelines through usability testing with disabled users. In Proc. of the 5th NordiCHI 2008, ACM (2008), 535538. http://dx.doi.org/10.1145/1463160.1463238

[23] Saowapakpongchai K., and Prougestaporn P. Web Accessibility Model for Visually Impaired Students on eLearning in Higher Ed- 
PAPER

Evaluating Web AcCESSiBility of EduCATIONAL Websites

ucation. International Journal of the Computer, the Internet and Management Vol.20 No.1 (January-April, 2012) pp34-42.

[24] Schmetzke D. Online distance education - "anytime, anywhere' but not for everyone. Information Technology and Disabilities, 7, (2) (2001).

[25] Seal j. A contextualized model of accessible e-learning practice in higher education institutions. Australian journal of educational technology. 2006, 22(2), 268-288

[26] Wattenberg T. "Beyond legal compliance: Communities of advocacy that support accessible online learning". Internet and Higher Education, (7), 123-139 (2004).

[27] Waits T., Lewis L. "Distance Education at Degree-Granting Postsecondary Institutions: 2000-2001". U.S. Department of Education, National Center for Education Statistics, NCES 2003-017, Washington, DC (Available http://nces.ed.gov/pubs2003/2003017.pdf) (2003).

[28] Wave detection tool. [Online]: http://wave.webaim.org/

[29] WebAIM: "The WebAIM Guide to Web Accessibility". WebAIM (2009), http://www.webaim.org (accessed January 12, 2010)

[30] W3C. (2005). "Essential components of web accessibility." [Online]: http://www.w3.org/WAI/intro/components.php
[31] W3C. (2006). "Authoring tools accessibility guideline." [Online]: http://www.w3.org/TR/ATAG20/

[32] 3PlayMedia. 2014. "2014 RoadMap to Web accessibility in higher Education". [online]: http://www.buffalo.edu/accessibility/14roadmapp.pdf

[33] Facts and Figures about disabilities. [Online]: http://www.edffeph.org/Page_Generale.asp?DocID=12534

[34] World Facts and Statistics on Disabilities and Disability Issues. [Online]: http://www.disabledworld.com/disability/statistics/

[35] Accessibility guidelines.

[Online]: http://www.exeter.ac.uk/staff/web/accessibility/

\section{AUTHOR}

Bayan Abu Shawar is with Information Technology and Computing Department, Arab Open University, Amman, 1339, Jordan (e-mail: b_shawar@aou.edu.jo).

Submitted 11 March 2015. Published as resubmitted by the author 20 August 2015. 